Supplement of Nat. Hazards Earth Syst. Sci., 16, 821-831, 2016

http://www.nat-hazards-earth-syst-sci.net/16/821/2016/

doi:10.5194/nhess-16-821-2016-supplement

(c) Author(s) 2016. CC Attribution 3.0 License.

(c) (1)

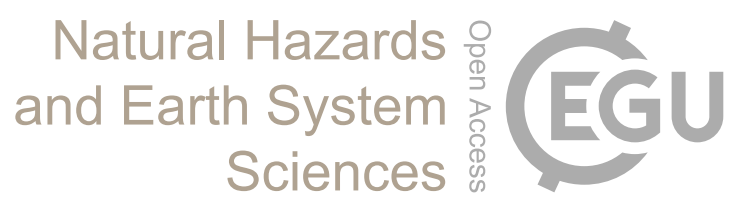

Supplement of

\title{
Magnitude and frequency of heat and cold waves in recent decades: the case of South America
}

\section{Guido Ceccherini et al.}

Correspondence to: Cesar Carmona-Moreno (cesar.carmona-moreno@jrc.ec.europa.eu)

The copyright of individual parts of the supplement might differ from the CC-BY 3.0 licence. 


\section{Supplement}

Figure S1 shows the maximum value in 5-year periods of the HWMItn from 1980 to 2014.

Figure S2 shows the maximum value in 5-year periods of the CWMI trom 1980 to 2014.

Figure S3 and Fig. S4 complement the analysis showing the annual values from 1980 to 2014 of HWMItx and $\mathrm{CWMI}_{\mathrm{tn}}$, respectively. 
HWMItn 1980-1984 HWMItn 1985-1989 HWMItn 1990-1994 HWMItn 1995-1999
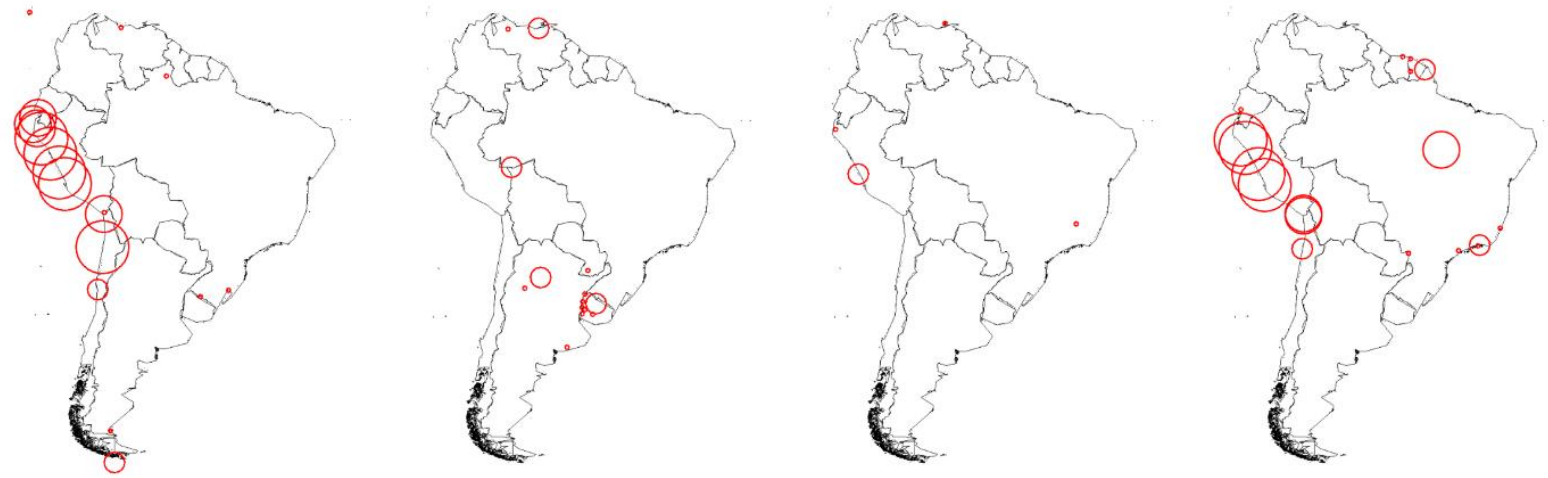

HWMItn 2000-2004
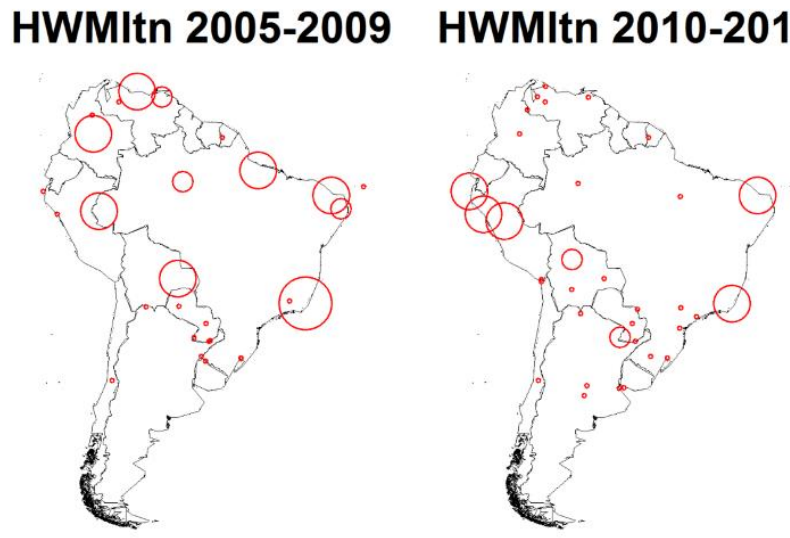

Magnitude

Scale

- 2-3

( $3-4$

( $4-8$

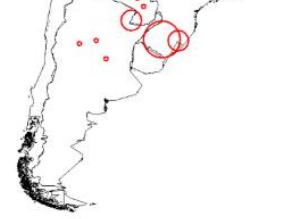

Figure S1 Magnitude of Heat Wave Index of minimum temperature $\left(\mathrm{HWMI}_{\mathrm{tn}}\right)$ for 5-year periods from 1980 to 2014. 


\section{CWMItx 1980-1984 CWMItx 1985-1989 CWMItx 1990-1994 CWMItx 1995-1999}
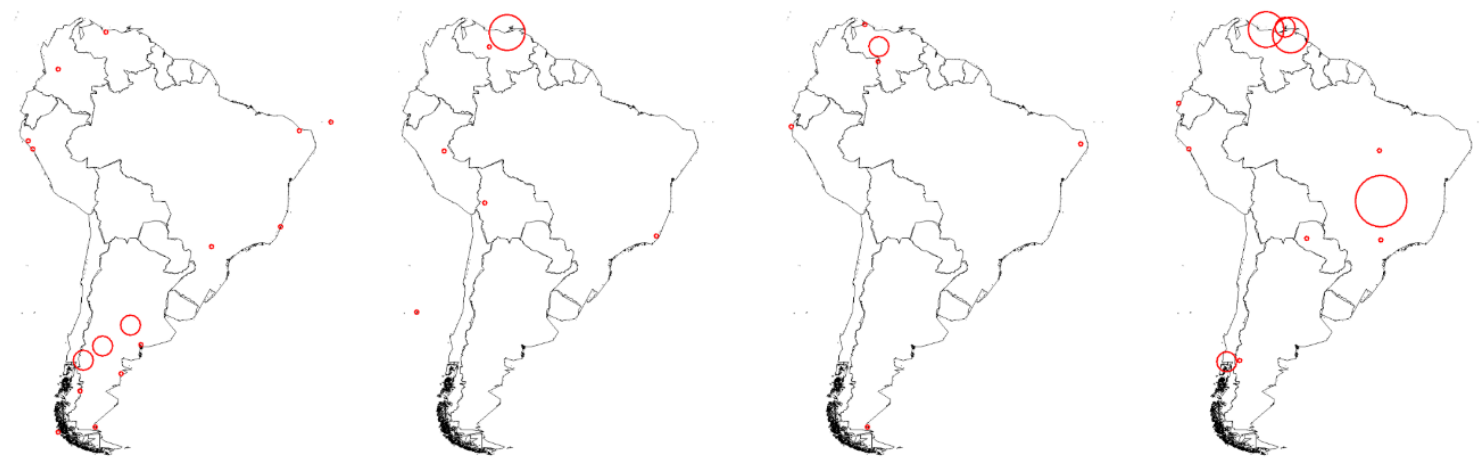

\section{CWMItx 2000-2004 CWMItx 2005-2009 CWMItx 2010-2014}
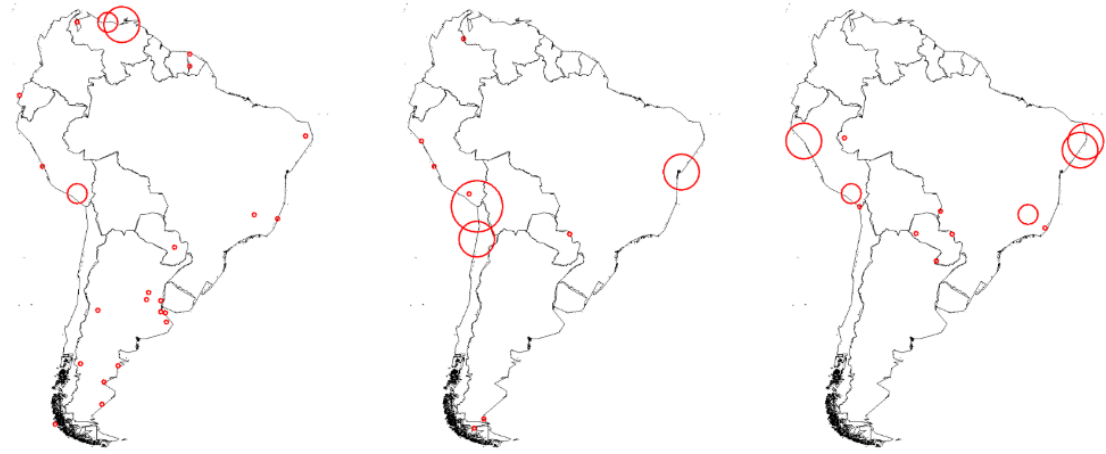

Magnitude

Scale

- $-2-3$

(1) $-3-4$

$-4-8$

$-8-32$

Figure S2 Magnitude of Cold Wave Index of maximum temperature (CWMI $)_{\mathrm{tx}}$ for 5-year periods from 1980 to 2014 
HWMItx1980

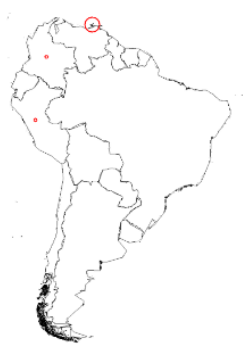

HWMItx1986

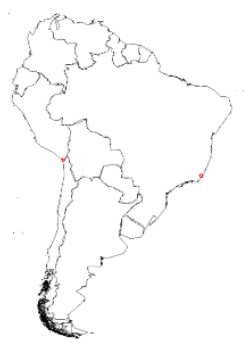

HWMItx1992

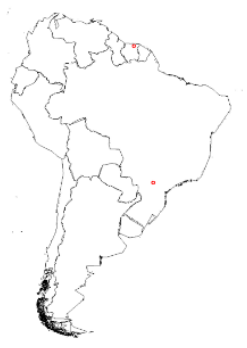

HWMItx1981

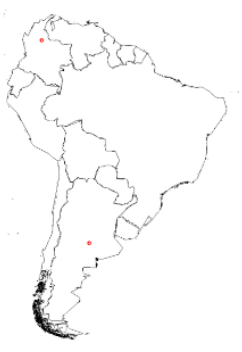

HWMItx1987

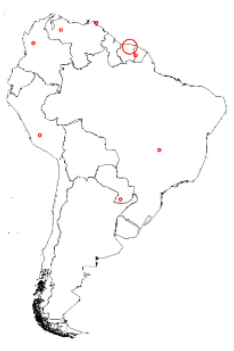

HWMItx1993

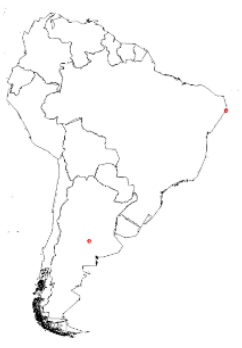

HWMItx1982

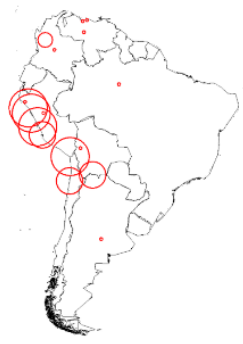

HWMItx1988

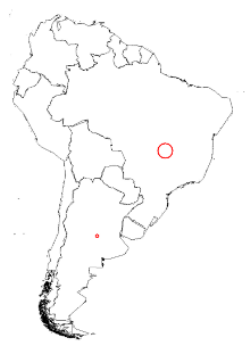

HWMItx1994

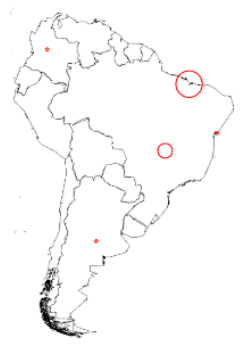

HWMItx1989

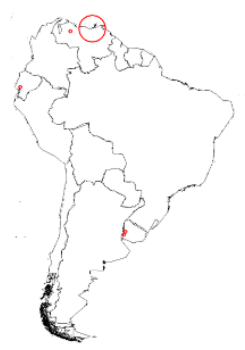

HWMItx1995 HWMItx1996

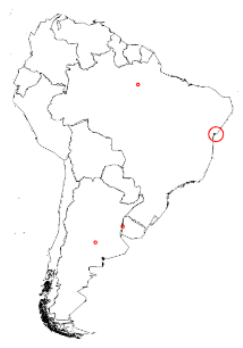

HWMItx1990

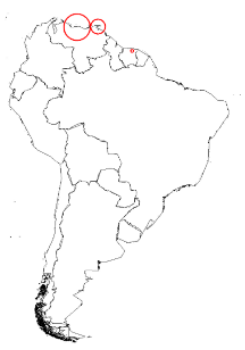

HWMItx1996 HWMItx1997
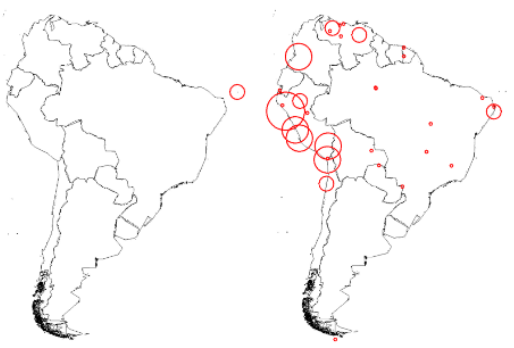

continue 

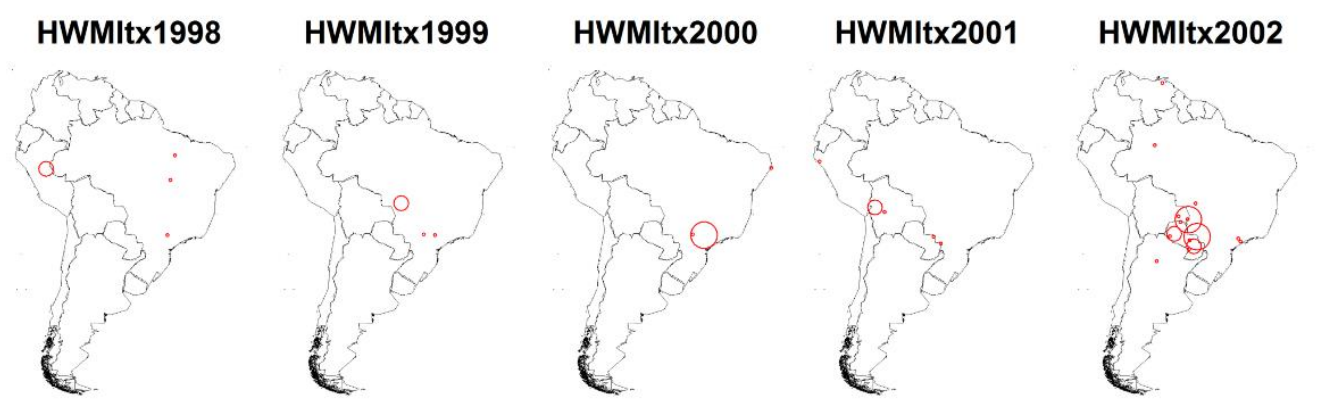

HWMItx2003
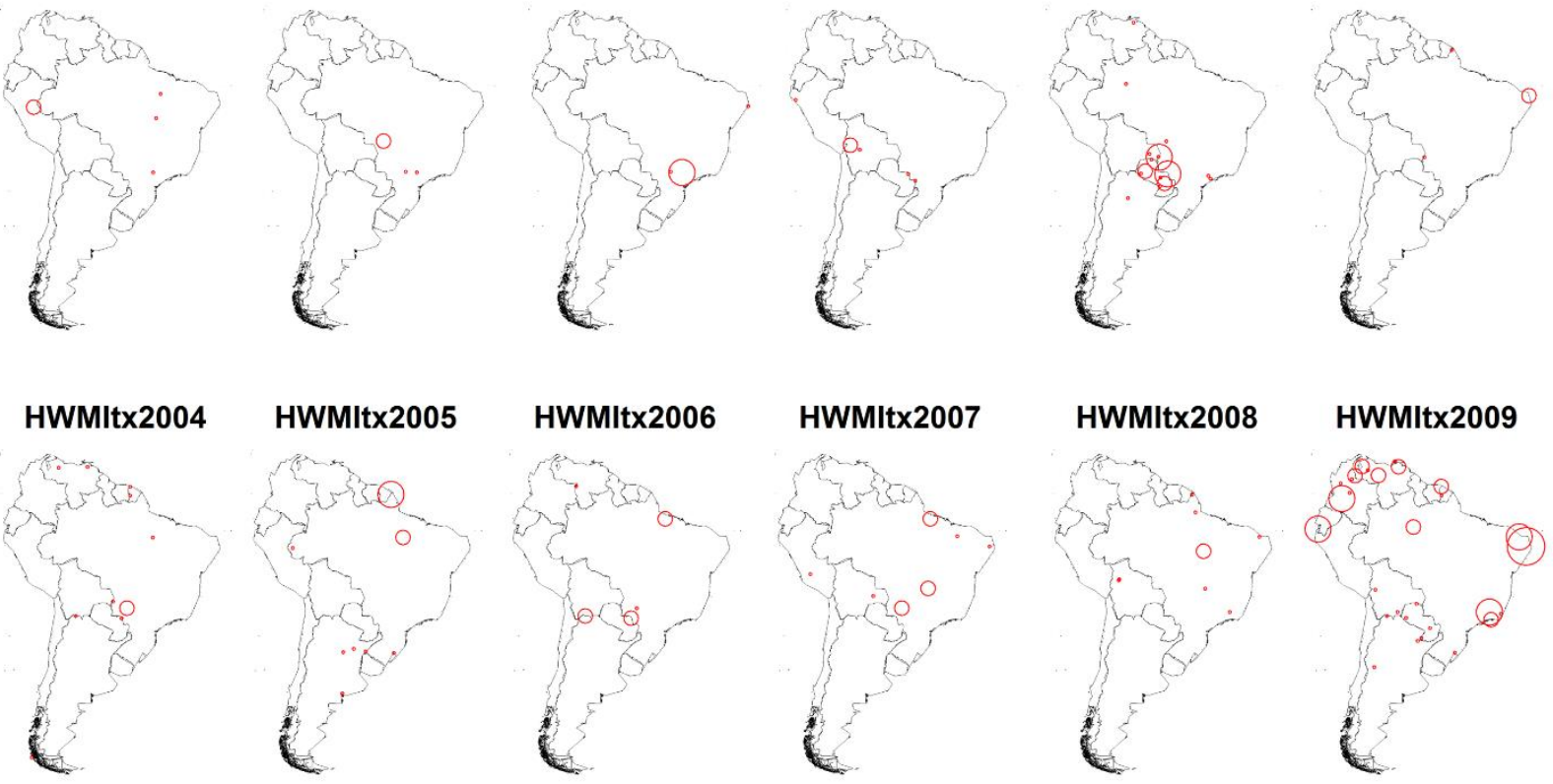

HWMItx2009
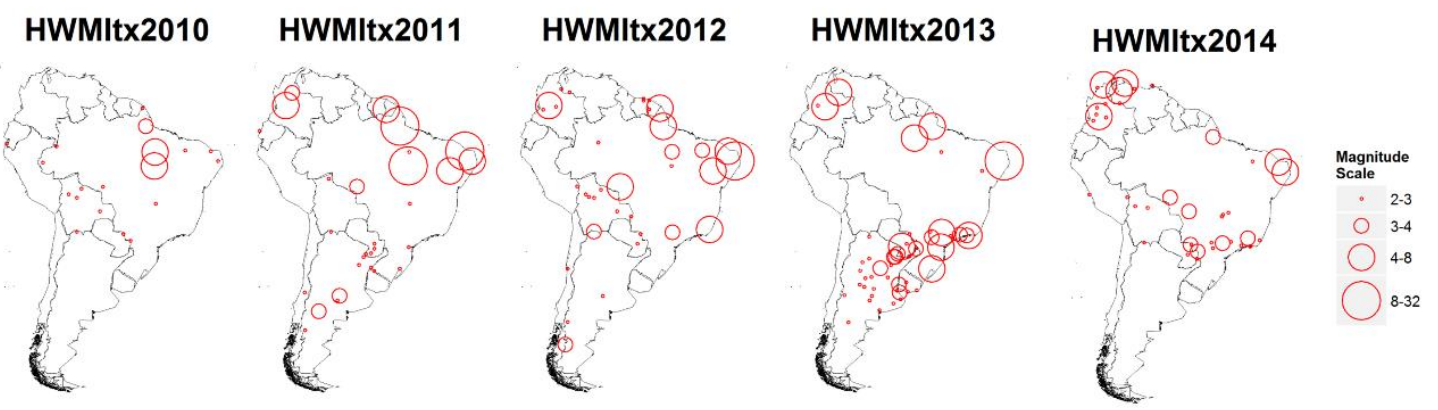

Figure S3 Annual values of Magnitude of Heat Wave Index of maximum temperature (HWMI $\mathrm{H}_{\mathrm{tx}}$ from 1980 to 2014. 

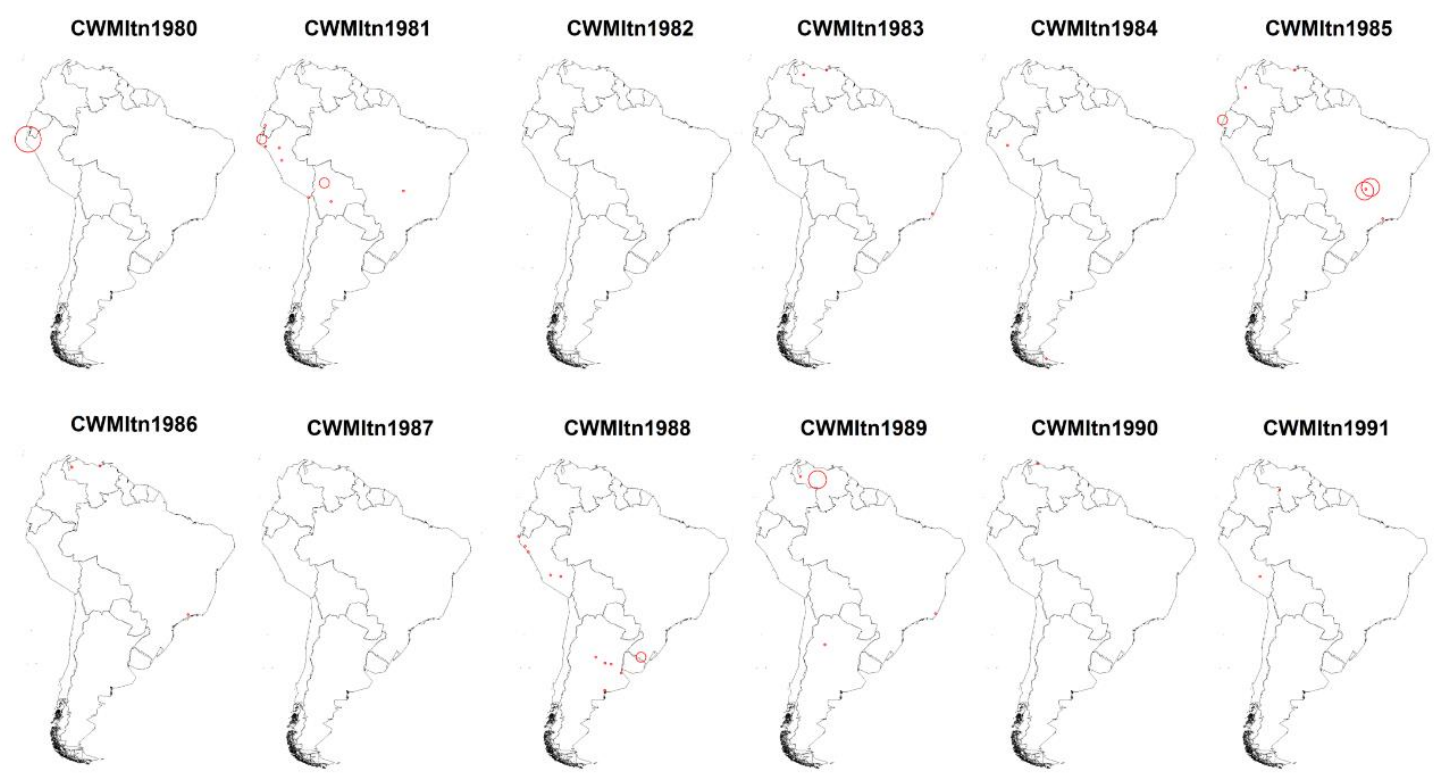

CWMItn1991
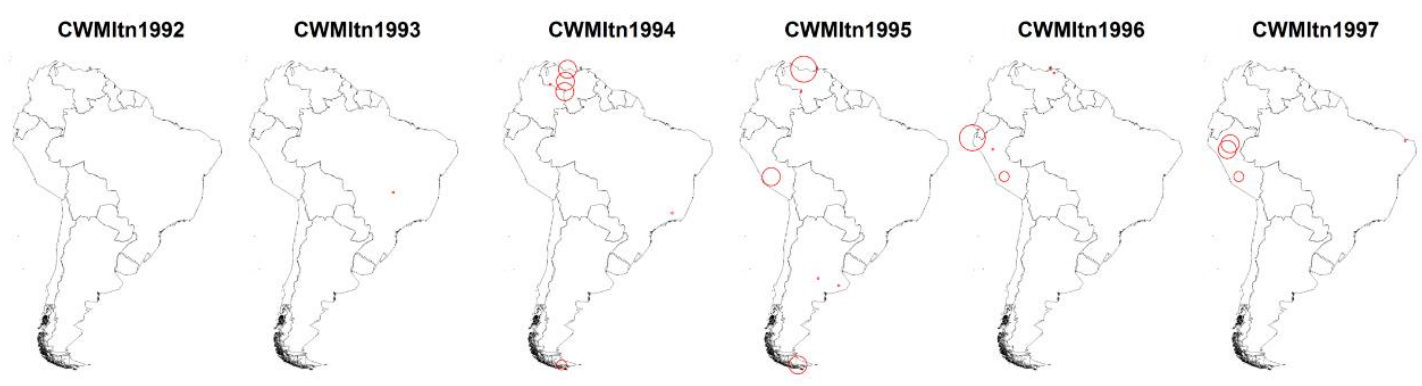

Continue 

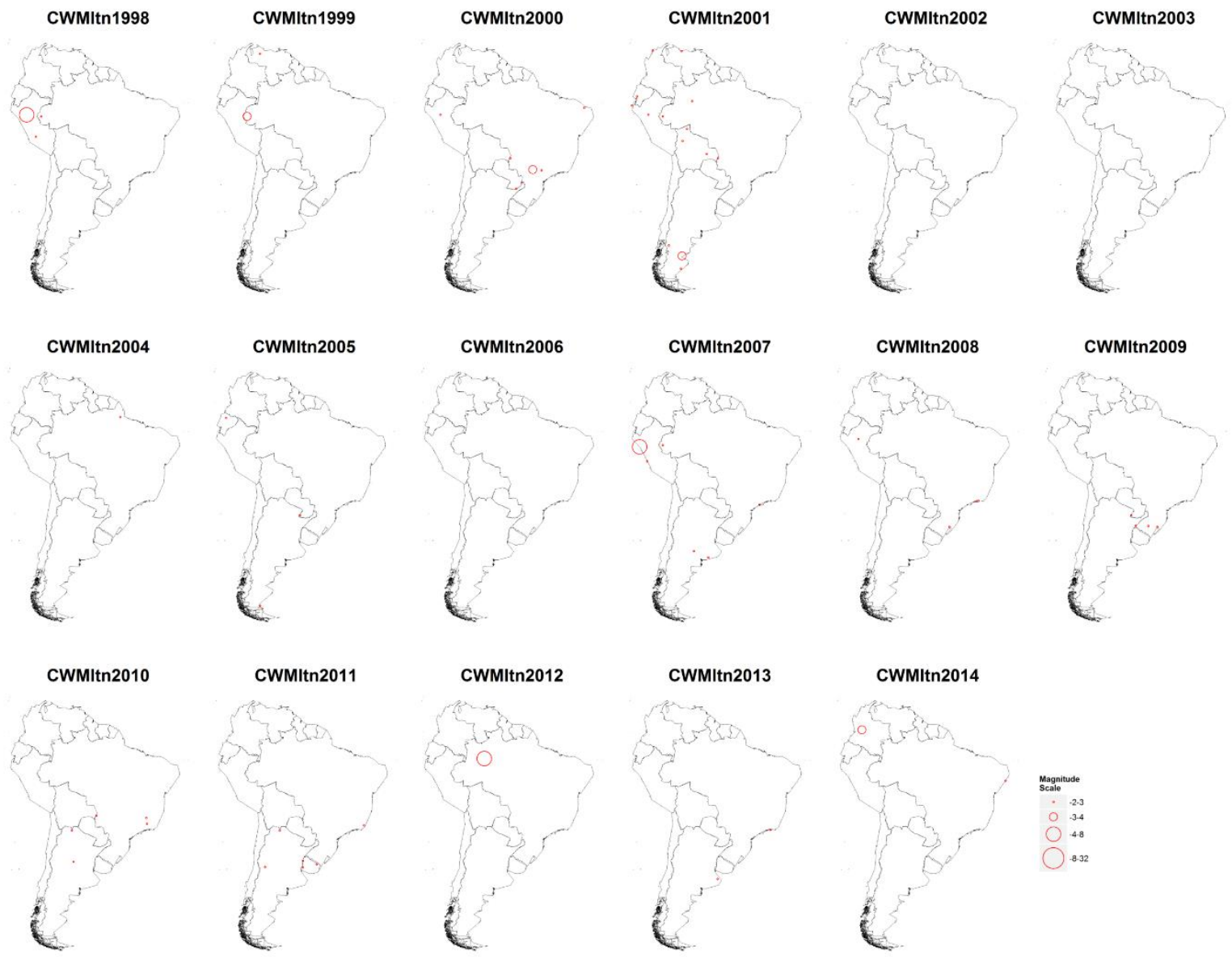

Figure S4 Annual values of Magnitude of Cold Wave Index of minimum temperature (CWMI $I_{\text {tn }}$ from 1980 to 2014. 